\title{
Using Demographics to Predict Mathematics Achievement Development and Academic Ability and Job Income Expectations
}

\author{
Mei-Shiu Chiu \\ Department of Education, National Chengchi University, Taiwan \\ Email: meishiuchiu@gmail.com
}

Received 21 June 2016; accepted 18 July 2016; published 25 July 2016

\begin{abstract}
This study investigated how demographics predict mathematics achievement development and how such development predicts academic ability and job income expectations. A hypothesis model was examined through growth modeling with data collected from students studying in grades 7,9 , 11 , and 12 in Taiwan $(n=4163)$. Data analysis revealed that the hypothesis model exhibited a good fit to the data. Compared with girls, boys exhibited higher mathematics achievement in both the start and growth of mathematics achievement. Parental education and speaking Mandarin and Taiwanese Hokkien at home played roles in both the start and growth of mathematics achievement. Speaking English at home exerted a positive effect on the start but not the growth of mathematics achievement. Speaking other foreign languages and Formosan languages at home exerted negative effects on both the start and growth of mathematics achievement. Family income and urban residence exerted a positive effect on the start but not the growth of mathematics achievement. Remote residence exerted a negative effect on the start but a positive effect on the growth of mathematics achievement. Both the start and growth of mathematics achievement played a role in students' expectations of academic ability and job income.
\end{abstract}

\section{Keywords}

Demographics, Expectations, Growth Modeling, Mathematics Achievement

\section{Introduction}

Achievement must be considered a developmental process with precedents and consequences to establish educationally meaningful measures for the desirable development of students. Considering mathematics achievement from a developmental perspective can elucidate the entire process of how achievement develops, how it can be initiated, and how it influences student careers. Previous mathematics achievement is an accurate predictor of future mathematics achievement [1]. Demographic factors serve as a basis of human development in a given society. Expectations provide a proxy for student career development. Therefore, this study used growth modeling to model the start and growth of adolescents' mathematics achievement with demographics as precedents and expectations as consequences and to examine the related effects. 


\subsection{Demographics and Mathematics Achievement}

Gender differences favoring boys in mathematics achievement have been a stereotype [2] that is supported in the literature [3]. However, gender differences in mathematics achievement vary among countries [4].

Socioeconomic status can include cultural capital and material capital. Cultural capital includes parental education and cultural heritage such as the language spoken at home. Cultural capital is typically positively related to mathematics achievement [4] [5], and the relationship of material capital with mathematics achievement is unknown.

Residence is a complex and context-dependent demographic. For example, in Germany, mathematics achievement is related to residence [6].

\subsection{Expectation and Mathematics Achievement}

Career expectations are typically positively related to mathematics achievement [7]. The relationship between self-concept and achievement was shown to be consistent in diverse domains including mathematics, reading, and science [8].

\subsection{Research Questions}

Based on a literature review, I propose a hypothesis model of mathematics achievement development, in which development is predicted by demographics, and academic ability and job income expectations are predicted by mathematics achievement development, as shown in Figure 1, with support from the data sources described in Section 2.1. Using the model, this study investigated the following three research questions:

1. To what extent does the hypothesis model fit the empirical data?

2. Do demographics predict mathematics achievement development?

3. Does mathematics achievement development predict academic performance and career expectations?

\section{Method}

\subsection{Data Sources}

Student and parent data collected during student grades 7, 9, 11, and 12 (four waves) were obtained from the Taiwan Education Panel Survey compiled by the Survey Research Data Archive, Taiwan. The sample comprised 4163 students (2, 55 boys and 2108 girls) and their parents.

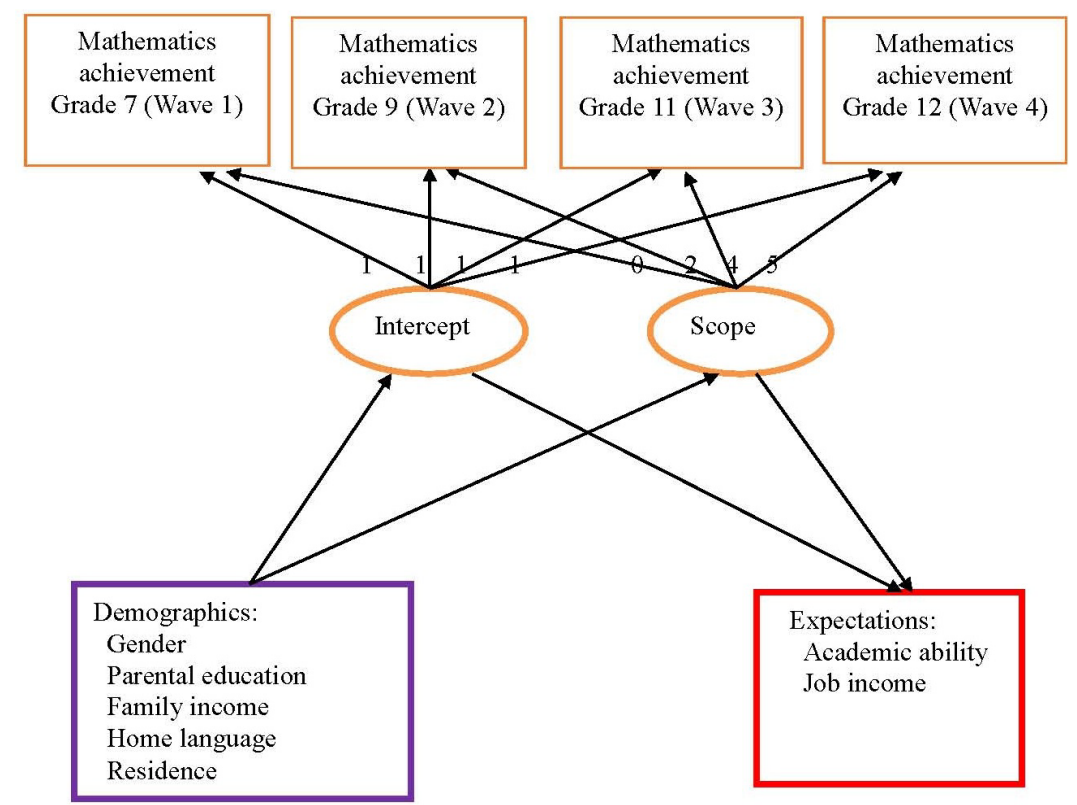

Figure 1. Hypothesis model of mathematics achievement development. 


\subsection{Measures}

- Mathematics achievement was measured using cognitive tests and was scaled according to item response theory. The scores obtained for the four waves are comparable.

- Gender was reported by students was scaled as $1=$ boy and $2=$ girl.

- Parental education was reported by the students' parents on a scale from $1=$ until Grade 9 to $5=$ postgraduate. This measure was calculated as the mean of the educational levels reported by the father and mother.

- Family income was provided by the students' parents on a scale from $1=<N T \$ 20,000$ to $6=>N T \$ 200,000$.

- Languages spoken at home were measured by asking students whether they spoke other languages at home (namely Mandarin, Taiwanese Hokkien, Hakka, Formosan languages, English, or other foreign languages, separately; $0=$ no, 1 = yes).

- Urban residence was measured by asking students to indicate the area they lived when studying in grade 7 . This was rescaled as $1=$ rural, $2=$ town, and $3=$ urban.

- Remote residence was measured by asking students to indicate whether they lived in remote areas of Taiwan when studying in grade $7(0=n o, 1=$ yes $)$.

- Academic ability expectation was measured by asking students about their ability expectations in terms of educational level; this was rescaled on a 5 -point scale from $1=$ senior high school to $5=P h D$.

- Job income expectation was measured by asking students their expected future income; this was also rescaled on a 5-point scale from $1=\leq N T \$ 30,000$ to $5=\geq N T \$ 150,001$.

\subsection{Data Analysis}

Growth modeling was performed to examine the hypothesis model (Figure 1) by using M plus software [9]. The model was considered a good fit to the data when the root mean square error of approximation (RMSEA) and standardized root mean square residual (SRMR) values were less than 0.080 and the comparative fit index (CFI) and Tucker-Lewis index (TLI) values were more than 0.900 [10]. A significant chi-square $\left(\chi^{2}\right)$ value was expected and was therefore not used as a criterion because of the large sample in this study [11].

\section{Results}

\subsection{Model Fit of the Hypothesis Model}

The hypothesis model (Figure 1) was accepted, as indicated by the fit index values (RMSEA $=0.073$, SRMR $=$ 0.031 , CFI $=0.900$, TLI $\left.=0.849, \chi^{2}=11962.865, d f=81, p<0.00005\right)$. The percentages of the dependent variables explained by the model were all significant at $p=0.05$ (Waves $1-4$ mathematics achievements: 88\%, $71 \%$, $79 \%$, 58\%; ability expectation: $13 \%$; income expectations: $2 \%$; intercept: $15 \%$; slope: $8 \%$ ). The negative intercept (start) in grade 7 and positive slope (growth) in later grades (Table 1) were consistent with the general positive trend of mathematics achievement development indicated by a previous study [3].

\subsection{Demographics Predicting Development}

In the present study, compared with boys, girls exhibited lower mathematics achievement in both the start and growth of mathematics achievement (Table 1). Parental education exerted positive effects on both the start and growth of mathematics achievement. However, family income exerted a positive effect only on the start but not growth of mathematics achievement.

Speaking Mandarin or Taiwanese Hokkien at home exerted positive effects on both the start and growth of mathematics achievement. Speaking Hakka exerted no effect. Speaking English at home exerted positive effects on the start but negative effects on the growth of mathematics achievement. Speaking other foreign languages and Formosan languages exerted negative effects on both the start and growth of mathematics achievement.

Urban residence exerted a positive effect on the start but not growth of mathematics achievement. Remote residence exerted a negative effect on the start but a positive effect on the growth of mathematics achievement.

\subsection{Development Predicting Expectations}

Students' expectations of both academic ability and job income can be predicted by the start and growth of mathematics achievement (Table 1). However, the effects tended to be moderate, with academic ability expectation being slightly higher than job income expectation. 
Table 1. Parameter estimates for the intercept and slope of mathematics achievement development predicted by demographics and predicting expectations.

\begin{tabular}{|c|c|c|c|}
\hline & \multirow{2}{*}{ Measures } & \multicolumn{2}{|c|}{ Mathematics achievement development } \\
\hline & & Intercept $=-0.626$ & Slope $=1.578$ \\
\hline \multirow[t]{11}{*}{ Predicted by demographics } & Gender (2 = girl; 1 = boy) & $-0.141^{\mathrm{a}}$ & -0.184 \\
\hline & Parental education & 0.255 & 0.231 \\
\hline & Family income & 0.057 & 0.000 \\
\hline & Home language: Mandarin & 0.205 & 0.271 \\
\hline & Home language: Taiwanese Hokkien & 0.068 & 0.117 \\
\hline & Home language: Hakka & 0.121 & -0.179 \\
\hline & Home language: Formosan languages & -0.698 & -0.644 \\
\hline & Home language: English & 0.004 & -0.330 \\
\hline & Home language:other foreign languages & -0.177 & -0.432 \\
\hline & Urban residence & 0.178 & 0.006 \\
\hline & Remote residence & -0.358 & 0.216 \\
\hline \multirow[t]{2}{*}{ Predicting expectations } & Academic ability & 0.398 & 0.296 \\
\hline & Job income & 0.113 & 0.104 \\
\hline
\end{tabular}

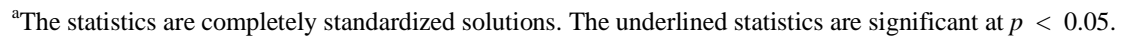

\section{Discussion}

\subsection{Strong Predictive Capacity of Demographics}

The support of the hypothesis model by growth modeling, as indicated by the fit index values and high variance of the dependent variable explained by demographics, suggests that demographics can predict the start and growth of mathematics achievement. The results are consistent with those of most related studies [1]-[8]. Furthermore, the results can be used to identify key measures to bridge demographic gaps by raising the achievement standards of disadvantaged students without decreasing those of advantaged students.

\subsection{Cultural Capital Matters and Indispensable Gender Inequality}

Demographics related to cultural capital (parental education and mainstream language speaking) are stronger predictors of the start and growth of mathematics achievement than those related to material capital (family income) and context-dependent capital (residence) are [6]. Family income and urban residence play a minor role in the start of mathematics achievement, but not in its growth. Educational policy measures should be designed to increase the cultural capital of families or schools when students are young to compensate for their initial disadvantages.

The language spoken at home is a complex consideration because cultural heritage should be preserved. A mutually beneficial strategy might be that ethnic minority families develop a culture of multiple languages, cultures, and identities to facilitate their children's achievement development without compromising their cultural heritage. This strategy requires support from society and the government, because ethnic minority families may lack mainstream cultural heritage.

Gender differences disadvantaging girls in mathematics achievements continue to occur in Taiwan, although their effect is small. Such differences start from the beginning of junior high school and persist till secondary education, suggesting that gender differences start early on, persist for a long time, and are rooted in culture. Cultural change is a difficult task but is still possible by raising public awareness of the detrimental effects of stereotyping [2] and increasing female roles in advancing mathematics achievements through educational interventions such as mass media and textbooks. 


\subsection{Moderate Capacity of Achievement Development in Predicting Expectations}

Students' expectations of their future academic ability and job income are directly predicted by the start and growth of students' mathematics achievement development and indirectly predicted by demographics with a moderate effect size. The results are consistent with previous findings that expectations and self-concept are related to achievement [7] [8]. The indirect role of demographics may be a long-term barrier to student career development. Educators should raise student awareness of demographic barriers, with the support of policy, to overcome these barriers and help students develop their careers on the basis of their ability rather than demographics.

\section{Acknowledgements}

This study was supported by the Ministry of Science and Technology, Taiwan (MOST 104-2410-H-004-143MY2).

\section{References}

[1] Grimm, K.J. (2008) Longitudinal Associations between Reading and Mathematics Achievement. Developmental Neuropsychology, 33, 410-426. http://dx.doi.org/10.1080/87565640801982486

[2] Good, C., Aronson, J. and Harder, J.A. (2008) Problems in the Pipeline: Stereotype Threat and Women's Achievement in High-Level Math Courses. Journal of Applied Developmental Psychology, 29, 17-28. http://dx.doi.org/10.1016/j.appdev.2007.10.004

[3] Hong, S. and You, S. (2012) Understanding Latino Children's Heterogeneous Academic Growth Trajectories: Latent Growth Mixture Modeling Approach. Journal of Educational Research, 105, 235-244. http://dx.doi.org/10.1080/00220671.2011.584921

[4] Organization for Economic Co-operation and Development (2014) PISA 2012 Results: What Students Know and Can Do-Student Performance in Mathematics, Reading and Science. Author, Paris.

[5] Chen, Q., Hughes, J.N. and Kwok, O.M. (2014) Differential Growth Trajectories for Achievement among Children Retained in First Grade: A Growth Mixture Model. Elementary School Journal, 114, 327-353. http://dx.doi.org/10.1086/674054

[6] Trautwein, U., Köller, O., Schmitz, B. and Baumert, J. (2002) Do Homework Assignments Enhance Achievement? A Multilevel Analysis in 7th-Grade Mathematics. Contemporary Educational Psychology, 27, 26-50. http://dx.doi.org/10.1006/ceps.2001.1084

[7] Dogan, H. (2012) Emotion, Confidence, Perception and Expectation Case of Mathematics. International Journal of Science and Mathematics Education, 10, 49-69. http://dx.doi.org/10.1007/s10763-011-9277-0

[8] Chiu, M.-S. (2012) Differential Psychological Processes Underlying the Skill-Development Model and Self-Enhancement Model across Mathematics and Science in 28 Countries. International Journal of Science and Mathematics Education, 10, 611-642. http://dx.doi.org/10.1007/s10763-011-9309-9

[9] Muthén, L.K. and Muthén, B.O. (2013) Mplus (Version 7.11) [Computer Software]. Author, Los Angeles.

[10] Hair Jr., J.F., Black, W.C., Babin, B.J. and Anderson, R.E. (2010) Multivariate Data Analysis: A Global Perspective. 7th Edition, Pearson Education, Upper Saddle River.

[11] Bollen, K.A. and Long, J.S. (1993) Testing Structural Equation Models. Sage, Newbury Park. 


\section{Submit or recommend next manuscript to SCIRP and we will provide best service for you:}

Accepting pre-submission inquiries through Email, Facebook, LinkedIn, Twitter, etc.

A wide selection of journals (inclusive of 9 subjects, more than 200 journals)

Providing 24-hour high-quality service

User-friendly online submission system

Fair and swift peer-review system

Efficient typesetting and proofreading procedure

Display of the result of downloads and visits, as well as the number of cited articles

Maximum dissemination of your research work

Submit your manuscript at: http://papersubmission.scirp.org/ 